\title{
EXPLORAÇÃo do SOFTWARE GEOGEBRA EM UM CURSO DE FORMAÇÃO CONTINUADA: UMA PROPOSTA DINÂMICA PARA O ESTUDO DE ISOMETRIAS DO TIPO ROTAÇÃO
}

\author{
EXPLORATION OF GEOGEBRA SOFTWARE IN A CONTINUED TRAINING \\ COURSE: A DYNAMIC PROPOSAL FOR THE ROTATION ISOMETRY
}

DOI: http://dx.doi.org/10.23926/RPD.2526-2149.2019.v4.n1.p42-60.id361

\section{Márcia Jussara Hepp \\ Rehfeldt}

Doutora em Informática na

Educação (UFRGS)

Professora titular da

Universidade Vale do

Taquari (UNIVATES)

mrehfeld@univates.br

\section{Edicionina Marinho \\ Gomes Oliveira \\ Mestre em Ensino de \\ Ciências Exatas \\ (UNIVATES) \\ Professora da Escola Básica no estado do Maranhão edicionina@hotmail.com}

\section{Rogério José Schuck \\ Professor do Mestrado e Doutorado em Ensino e Mestrado em Ensino de Ciências Exatas \\ (UNIVATES) \\ rogerios@univates.br}

Resumo: Este artigo apresenta um estudo de isometrias de rotação. O estudo é parte de um curso de formação continuada decorrente de uma dissertação de Mestrado, apresentada ao programa de PósGraduação em Ensino de Ciências Exatas, da Universidade do Vale Taquari, Univates. O curso envolveu cinco professores de Matemática, do $6^{\circ}$ ao $9^{\circ}$ ano, de uma escola da Rede Pública de Amarante do Maranhão/MA. Foram abordadas atividades de isometrias de rotação, com possibilidade de exploração com ou sem o uso do software GeoGebra. Como instrumentos de coleta de dados foram utilizadas as atividades propostas aos professores e respondidas por eles, as gravações de áudios e vídeos, a observação e o diário de campo da pesquisadora. Os resultados apontaram que o curso de formação continuada contribuiu para a incorporação do software GeoGebra, como recurso tecnológico, na prática dos professores, indicando mudanças futuras, dado $\mathrm{o}$ interesse demonstrado nos encontros de formação.

Palavras-chave: Isometrias de rotação. GeoGebra. Formação de professores.

\begin{abstract}
This paper presents a study of rotation isometries. The study is part of a continuing education course and integrates a Master's thesis, presented to the Graduate Program in Teaching of Exact Sciences, University of Vale do Taquari, Univates. The course involved five Mathematics teachers, from the 6th to 9th grades, from a public school located in Amarante do Maranhão / MA. Were studied rotational isometry activities, with the possibility of exploration with or without the use of GeoGebra software. As data collection instruments, the activities proposed to the teachers as well as the obtained results, the audio and video recordings, the observation and the field diary of the researcher were used. The results showed that the continuous training course contributed to the incorporation of GeoGebra software as a technological resource in the teachers' practice, indicating future changes, given the interest shown in the continuous training courses.

Keywords: Rotation isometries. GeoGebra. Teacher training.
\end{abstract}




\section{INTRODUÇÃO}

A formação continuada de professores busca promover melhorias para o ensino e agregar inovações pedagógicas à prática docente. Na maioria das escolas, essas formações acontecem todos os anos. No entanto, algumas não oferecem cursos de capacitação envolvendo recursos tecnológicos. Nesse sentido, Tajra (2012) elucida que os professores necessitam ser capacitados, habilitados para tal, considerando que são essenciais para o sucesso de implantação dos recursos tecnológicos nos ambientes escolares. Entende-se que a inserção das Tecnologias Digitais de Informação e Comunicação (TDICs) ${ }^{1}$ não substitui o professor, mas pode promover mudanças de postura em relação ao ensino.

Segundo Carvalho e Gil-Pérez (2011), em algumas situações de ensino, é possível observar educadores que não conseguem visualizar as carências de suas próprias práticas. Por vezes, não percebem a necessidade de desenvolver diferentes saberes, tampouco se apresentam como professores ousados, com domínio e conhecimento das transformações da atualidade. De acordo com os autores supramencionados, os cursos de formação docente que visam às mudanças didáticas precisam mostrar essas carências e oferecer opções executáveis.

Neste cenário, o estudo de isometrias de rotação, desenvolvido por meio do software GeoGebra e apresentado neste trabalho, pode ser um exemplo de formação de professores exequível em escolas com pouco uso de tecnologias. O estudo é parte de uma pesquisa de Mestrado apresentada ao programa de Pós-Graduação em Ensino de Ciências Exatas da Universidade do Vale Taquari, Univates. Especificamente, a pesquisa objetivou desenvolver uma proposta de formação continuada junto aos professores de Matemática do $6^{\circ}$ ao $9^{\circ}$ ano de uma escola de Rede Pública de Amarante do Maranhão/MA, considerando a possibilidade de identificar as carências desses educadores em relação ao uso das tecnologias na sala de aula e caminhos praticáveis para rever parte dessas dificuldades.

Assim, esse trabalho justificou-se em função de lacuna constatada nas práticas pedagógicas em relação ao uso de tecnologias, visto que os professores citados ainda não haviam participado de cursos de formação continuada que favorecessem o uso das TDICs atreladas ao ensino. Também, pela relevância da temática, pois, segundo Borba e Penteado

\footnotetext{
${ }^{1}$ Gewehr (2016), embasado em autores como Miskulin et al. (2006), Cardoso (2011), Leite (2014) e Kenski (2012), menciona que o termo é usado para expressar a convergência de distintos recursos como a informática, as telecomunicações, agrupando ferramentas computacionais e meios comunicativos como rádio, televisão, vídeo e internet, objetivando a difusão de informações. Mais recentemente foi inserida a letra D de digital, o que representou uma tecnologia mais avançada.
} 
(2015), o curso de formação continuada com o uso de tecnologias objetiva superar as práticas antigas, isto é, promover o professor a um ator com saber informático.

Dessa forma, visando a contribuir para a implantação de metodologias inovadoras na prática docente de professores de Matemática, este trabalho aborda um estudo de isometrias de rotação, desenvolvido em dois encontros presenciais de duas horas cada, num curso de formação continuada realizado com cinco professores de Matemática. O curso gerou nos professores, além do entendimento de suas carências pedagógicas, conhecimento para explorar o software GeoGebra junto aos educandos, agregando, assim, mudanças nas suas práticas docentes.

\subsection{Formação CONTINUAda de PROFESSORES E OS DESAFIOS PROMOVIDOS PELAS TECNOLOGIAS DIGITAIS}

De forma geral, os cursos de formação continuada contemporâneos buscam apresentar aos professores, propostas metodológicas engajadas no processo de transformação e de mudança das práticas docentes. Ademais, procuram agregar os fenômenos e os recursos do mundo moderno ao ensino, de modo a conscientizar que a ênfase da atividade docente deve situar-se "num processo de transformação e mudança em que se desenrolam os fenômenos humanos, captando a questão no seu desenvolver, isto é, no seu processo, uma vez que todos são coparticipantes ativos e sujeitos da construção e transformação do conhecimento" (FREITAS, 2009, p. 66).

Num olhar retrospectivo sobre a história do ensino, Silva (2008) aborda que os professores precisam ficar atentos para compreender as mudanças dos tempos que estamos vivendo. Eles devem perceber que as formas de produzir conhecimento não obedecem mais a uma lógica vetorial. Precisam ver a educação em diferentes aspectos e perceber as múltiplas possibilidades que ela pode apresentar, os diversos olhares que ela impõe, encarando a realidade da contemporaneidade. Freitas (2009) argumenta que a contemporaneidade exige que o ensino proponha dinâmicas pedagógicas que não se restrinjam à transmissão ou disponibilização de informação, mas insiram nessas dinâmicas as tecnologias digitais de informação e comunicação.

Nessa perspectiva, Borba, Silva e Gadanidis (2014) argumentam que o acesso à informática na sala de aula deve ser entendido como um direito. As tecnologias devem estar inseridas em atividades essenciais, tais como: aprender a ler, compreender textos, escrever, entender situações matemáticas, contar, desenvolver noções espaciais, dentre outras. Para 
complementar essa ideia, Tajra (2012) esclarece que as tecnologias possibilitam ao usuário, comunicar-se, pesquisar, criar desenhos, efetuar cálculos, simular fenômenos, entre muitas outras ações. Nenhum outro recurso didático oferece tantas oportunidades de utilização. Ademais, são as tecnologias que estão no fastígio da sociedade moderna.

Contudo, entende-se que esse processo ainda é um grande desafio. Observa-se que as ferramentas tecnológicas contemporâneas, como computadores, internet e celulares, são utilizadas pelos alunos, para vários fins, enquanto os professores ainda se limitam a desenvolver apenas algumas das competências que as TDICs contemplam. Segundo Tajra (2012), o educador que atua como agente mediador do processo do conhecimento e que prepara o indivíduo para a vida necessita integrar à sua prática pedagógica as ferramentas necessárias para a concretização desse processo, entre as quais, o computador, a internet e toda potencialidade que essas ferramentas oferecem.

Cabe destacar, entretanto, que não basta apenas inserir as tecnologias no contexto educacional. De acordo com Silva (2008), os professores necessitam aprofundar sua visão sobre elas e sobre o seu próprio papel como agentes educativos. Precisam questionar os significados que lhes são instituídos e as situações novas com que se defrontam. Precisam procurar respostas e modos de ação próprios, construídos coletiva e cooperativamente. Diante disso, entende-se que o processo de construção de conhecimento com o uso de tecnologias acontece a partir do que o educador sabe fazer com elas, ou seja, a prática está relacionada aos saberes que professor possui sobre a ferramenta que pretende usar na sala de aula.

Compreende-se também que os processos de ensino e de aprendizagem não florescem apenas no saber fazer. Freitas (2009) comenta que não basta ter acesso à informação para o aprendizado fazer sentido. É preciso que cada indivíduo entre em ação e deixe de ser um mero receptor, para tornar-se também emissor e criador de informações e de conhecimento. Tajra (2012) menciona que é indispensável que os educadores possam visualizar os caminhos que querem seguir e que estejam aptos a participar dos processos de ensino e de aprendizagem que realmente preparem cidadãos conscientes de seus direitos e deveres numa sociedade globalizada.

Assim, cientes de que a formação continuada de professores traz situações específicas que conduzem o corpo docente à obtenção de novos conhecimentos e à construção de novas propostas de ensino, neste relato apresenta-se um trabalho em que foi explorado o software GeoGebra, num estudo de isometrias de rotação. Este software é classificado por Borba, Silva e Gadanidis (2014) como um software de caráter inovador, por referir-se a uma tecnologia 
pioneira na integração do ensino de Matemática. Compreende-se que o uso de práticas com softwares educativos busca ultrapassar as técnicas retrógradas, promovendo um novo saber. Saber este que, de acordo com Borba e Penteado (2015), está em harmonia com uma visão de construção de conhecimento que concede vantagens ao processo e não ao produto/resultado em sala de aula. Um saber científico que compreende o conhecimento como uma situação que depende do sujeito.

No entanto, tal prática ainda é difícil de ser concebida em muitas salas de aula de Matemática, mesmo que as tecnologias digitais disponham de vários softwares que podem ser importantes aliados ao ensino de Matemática. Silva (2008) acrescenta que as tecnologias, com suas diversas ferramentas podem representar diversas possibilidades pedagógicas a serem incorporadas pelo professor, com o objetivo de acender nos alunos o desejo de aprender a aprender, o entusiasmo pelo conhecimento e, principalmente, o prazer e a alegria da descoberta.

\section{Desenvolvimento}

A abordagem escolhida para o desenvolvimento do trabalho aqui apresentado foi a qualitativa. Conforme Borba e Araújo (2013, p. 116), a pesquisa qualitativa "engloba a ideia do subjetivo, passível de expor sensações e opiniões. O significado atribuído a essa concepção de pesquisa também engloba noções a respeito de diferenças e semelhanças de aspectos comparáveis de experiências".

Essa pesquisa também pode ser considerada como um estudo de caso. Segundo Godoy (2005), o estudo de caso se caracteriza como um tipo de pesquisa cujo objeto é uma unidade que se analisa profundamente, visando à apreciação detalhada de um espaço, de um simples sujeito ou de uma circunstância em particular. A autora ainda alude que o estudo de caso tem se tornado o tipo de pesquisa preferido por investigadores que buscam respostas para questões do tipo "como" e "por quê" certos fatos acontecem, ou quando há pouca possibilidade de influência sobre os eventos estudados, ou, ainda, quando o foco de interesse são situações da contemporaneidade, que só poderão ser pesquisadas dentro de alguma situação de vida real. Neste estudo, o intuito foi encontrar uma resposta à questão como uma prática utilizando o software GeoGebra pode contribuir na formação de professores de Matemática.

Para Borba e Araújo (2013), essa metodologia supõe a utilização de diferentes procedimentos para a obtenção de informações durante a coleta de dados. Assim, compreendese que, por tratar-se de uma pesquisa de cunho qualitativo, com essa metodologia é possível obter um maior número de informações, empregando fontes e métodos diferenciados. 
Dessa forma, buscando coletar bons dados, foram utilizados como instrumentos de coleta de informações, gravações de áudios e vídeos, diário de campo e as atividades respondidas pelos professores. Já o diário de campo, conforme Lewgoy e Arruda (2004), consiste em um instrumento apropriado que permite o exercício acadêmico na busca da identidade profissional, pois, por meio de aproximações consecutivas e críticas, pode-se realizar uma reflexão da ação profissional cotidiana, revendo seus limites e desafios.

Para qualificar a obtenção de dados, também foi utilizada a observação. De acordo com Marconi e Lakatos (2014), observar significa utilizar todos os sentidos para a obtenção de determinados aspectos da realidade. Não consiste apenas em olhar e escutar, mas, sim, em examinar os fatos ou o fenômeno que está sendo investigado.

Para apresentar os resultados, optou-se, neste artigo, pelo método descritivo. Segundo Marconi e Lakatos (2014), a análise descritiva tem como objetivo apreciar a natureza do fenômeno estudado, a forma como ele se constitui, as características e os processos que dele fazem parte. Nas pesquisas descritivas, o pesquisador procura apreciar e interpretar a realidade, sem nela interferir para poder modificá-la.

Posto isso, na seção a seguir, apresenta-se o estudo de isometrias de rotação, usando como recurso tecnológico, o software GeoGebra, junto a cinco professores de Matemática, que foram identificados pelas letras A, B, C, D e E. O objetivo das atividades foi levar os professores a desenvolverem movimentos de rotação das figuras em relação ao ponto zero, explorando as ferramentas do software GeoGebra. Foram implementadas com cinco professores de Matemática, que atuam nas turmas de $6^{\circ}$ ao $9^{\circ}$ ano de uma escola da Rede pública de Amarante do Maranhão/MA.

Considerando que este relato apresenta um recorte de uma dissertação de Mestrado, destaca-se que no curso de formação continuada houve outros encontros anteriores e posteriores aos dois que estão sendo descritos aqui. Assim, nos dois encontros descritos, os professores já haviam adquirido habilidades para manusear o software GeoGebra, as quais não tinham nos primeiros encontros do curso. As atividades descritas neste relato foram desenvolvidas no sexto e no sétimo encontro da formação, de um total de 10 encontros, sendo que cada um deles teve duração de duas horas.

Para desenvolver a formação continuada, as atividades propostas aos professores foram impressas (Quadro 1) e entregues aos docentes, a fim de que pudessem resolvê-las, também de forma "manual", sem o uso do software, caso quisessem, em outro momento. 
Quadro 1 - Atividades de isometrias de rotação

\section{Atividades envolvendo simetria de rotação \\ a) No sentido anti-horário com rotação de $180^{\circ}$. \\ b) No sentido anti-horário de $45^{\circ}$. \\ c) No sentido horário com rotação de $90^{\circ}$. \\ d) No sentido horário com rotação de $130^{\circ}$.}

1) Desenhe a figura de uma seta de acordo com a imagem a seguir em qualquer lugar do plano cartesiano do software GeoGebra. Em seguida, desenhe um ponto $\mathrm{O}$ no centro do plano cartesiano e faça a reflexão de rotação da imagem em relação ao ponto que está no centro dos eixos x e y das seguintes formas:

2) Desenhe a imagem do triângulo abaixo no software GeoGebra, respectivamente, por rotação de $90^{\circ}$, $180^{\circ}$, e $270^{\circ}$, no sentido horário e anti-horário em torno do centro de rotação 0 .

Fonte: dos autores

Atribua para $\mathrm{A}(-1,0), \mathrm{B}(-3,0)$ e $\mathrm{C}(-5,2)$ e responda:

a) Se houver uma rotação de $90^{\circ}$ no sentido anti-horário em relação ao ponto $\mathrm{O}$, onde vai parar o ponto A?

b) Se houver uma rotação de $180^{\circ}$ no sentido anti-horário em relação ao ponto $\mathrm{O}$, onde vai parar o ponto B?

c) Se houver uma rotação de $270^{\circ}$ no sentido anti-horário em relação ao ponto $\mathrm{O}$, onde vai parar o ponto $\mathrm{C}$ ?

d) Se houver uma rotação de $90^{\circ}$ no sentido horário em relação ao ponto $\mathrm{O}$, onde vai parar o ponto A?

e) Se houver uma rotação de $180^{\circ}$ no sentido horário em relação ao ponto $\mathrm{O}$, onde vai parar o ponto C?

f) Se houver uma rotação de $270^{\circ}$ no sentido horário em relação ao ponto $\mathrm{O}$, onde vai parar o ponto $\mathrm{B}$ ?

3) Desenhe a figura abaixo a partir dos pontos $\mathrm{A}(3,3), \mathrm{B}(1,2), \mathrm{C}(4,1), \mathrm{D}(7,2)$ e $\mathrm{E}(4,2)$.

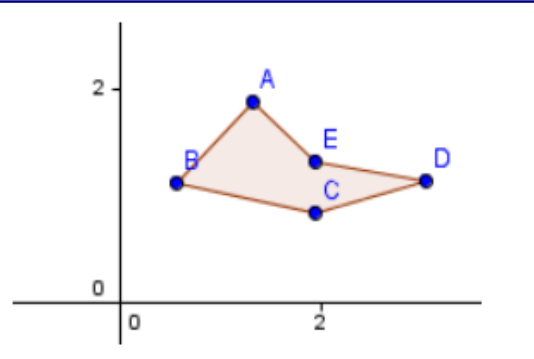

a) Se houver uma rotação de $90^{\circ}$ em relação ao ponto D no sentido anti-horário, onde vai se situar o ponto $\mathrm{D}$ ?

b) Se houver uma rotação de $180^{\circ}$ em relação ao ponto B no sentido anti-horário, onde vai se situar o ponto $\mathrm{B}$ ?

a) Se houver uma rotação de $180^{\circ}$ em relação ao ponto B no sentido horário, onde vai se situar o 
ponto B?

b) Se houver uma rotação de $45^{\circ}$ em relação ao ponto $\mathrm{C}$ no sentido anti-horário, onde vai se situar o ponto E?

c) Se houver uma rotação de $120^{\circ}$ em relação ao ponto E no sentido anti-horário, onde vai se situar o ponto E?

f) Como você pensou para responder a atividade?

g) Confira agora usando o software GeoGebra. Quais respostas você errou? Por quê?

4) Escreva com suas palavras o que é simetria de rotação.

\section{Fonte: dos autores}

\subsection{ESTUDO DE ISOMETRIAS DE ROTAÇÃO}

Com as atividades impressas nas mãos, cada professor utilizou o seu computador para construir a figura de uma seta, projetada na atividade a partir de pontos. Em seguida, eles realizaram movimentos de rotação das imagens em relação a pontos distintos, no sentido horário e anti-horário, realizando voltas de até $270^{\circ}$, operando o software GeoGebra. As Figuras 1, 2, 3 e 4 são produções dos professores, estabelecidas a partir do GeoGebra, executando movimentos de rotação em graus de uma imagem situada em locais diferentes do plano do software.

Figura 1 - Rotação de $180^{\circ}$ de uma imagem posicionada em locais diferentes de um plano

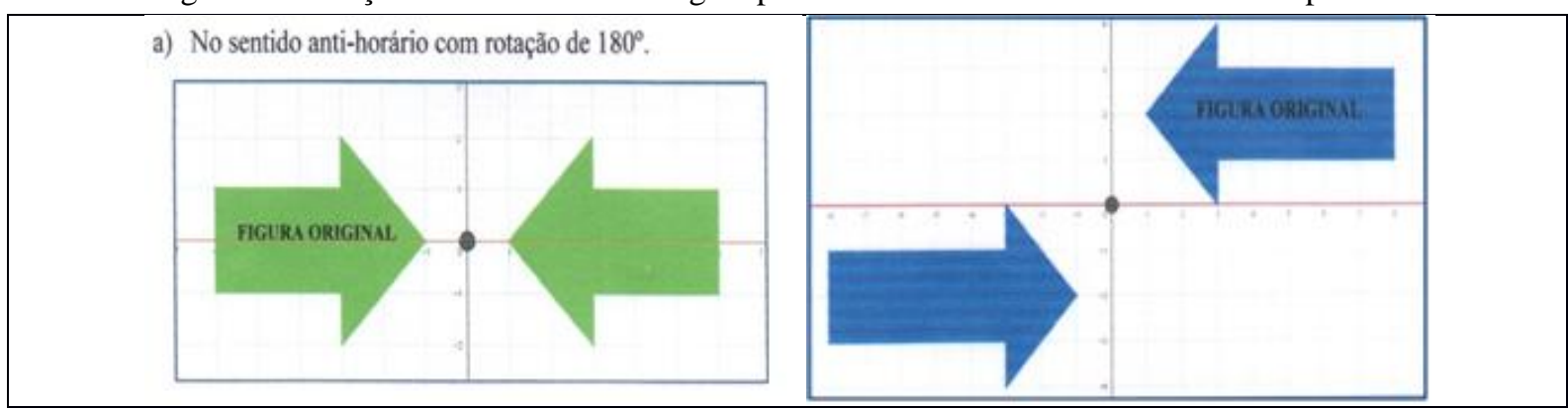

Fonte: Professores B e E.

Na Figura 1, pode-se observar a rotação de $180^{\circ}$ da seta (figura original). O professor B manteve a seta original verde e a girou mantendo a simetria em relação ao eixo y. Da mesma forma, o professor E realizou a rotação, porém deslocou a seta azul original em 4 unidades, no eixo y, para baixo.

Figura 2 - Rotação de $45^{\circ}$ de uma imagem posicionada em locais diferentes de um plano

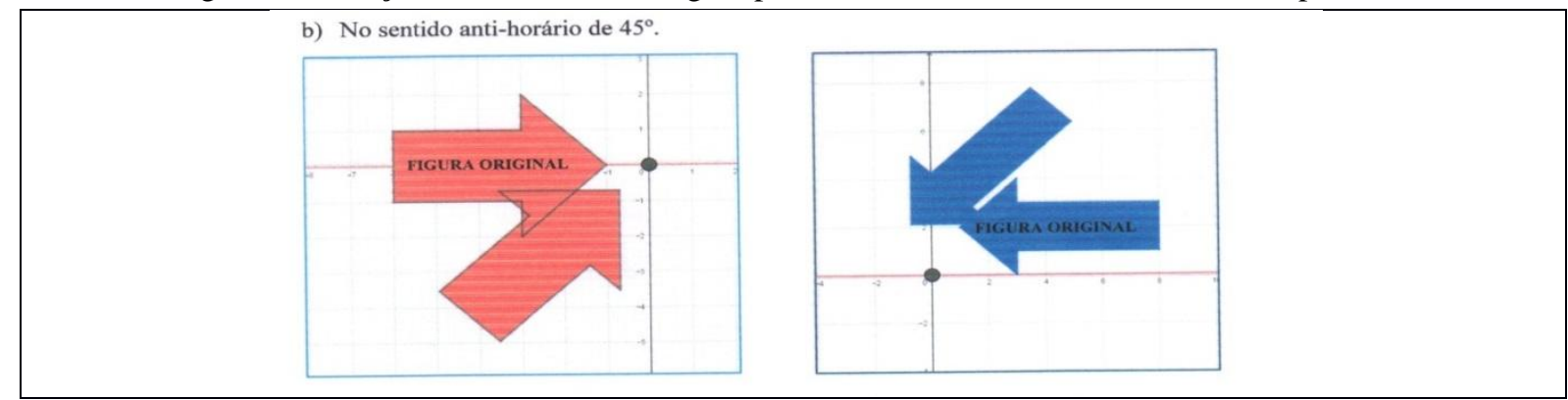

Fontes: Professores A e E. 
$\mathrm{Na}$ Figura 2, a rotação, a partir da figura original, foi de $45^{\circ}$. Ambos os professores utilizaram o sentido anti-horário, porém o deslocamento da seta ocorreu de forma diferenciada. A ponta da seta vermelha foi deslocada em uma unidade para direita e uma unidade para baixo. Distintamente, a ponta da seta azul foi deslocada duas unidades para a esquerda, mas não alterou a posição da altura no eixo $\mathrm{y}$.

Figura 3 - Rotação de $90^{\circ}$ de uma imagem posicionada em locais diferentes de um plano

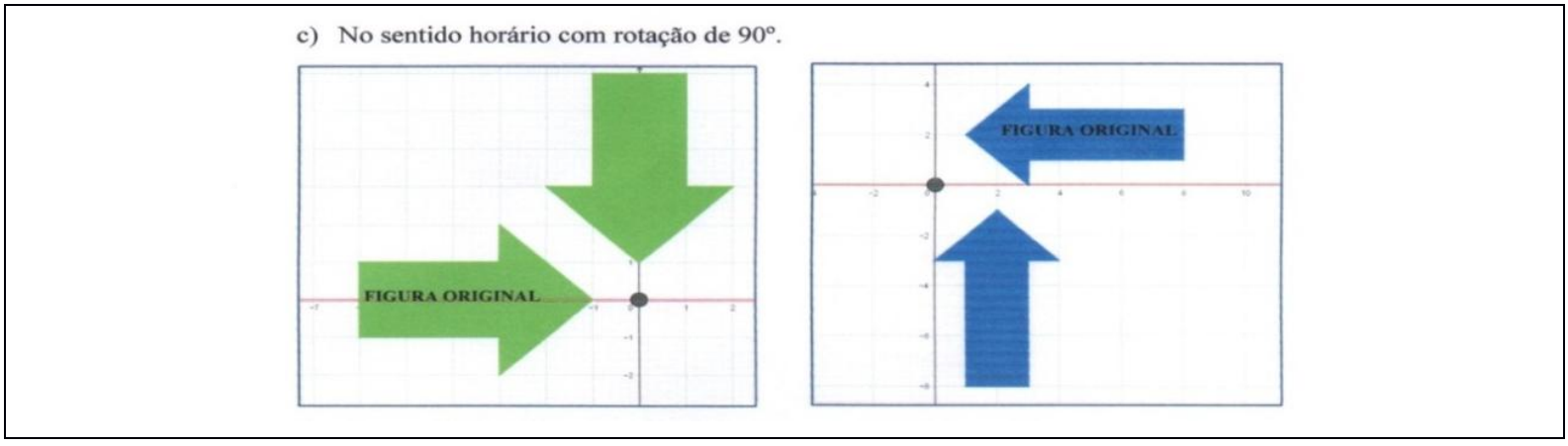

Fontes: Professores B e E.

Na Figura 3, é interessante observar que os professores B e E giraram suas figuras originais em $90^{\circ}$, mas, desta vez, no sentido horário. O professor B manteve a seta verde a uma unidade de distância do ponto $(0,0)$. Já o professor E posicionou a ponta da seta trocando o eixo x pelo eixo y, embora a distância tenha se mantido em duas unidades de medida.

Figura 4 - Rotação de $130^{\circ}$ de uma imagem posicionada em locais diferentes de um plano

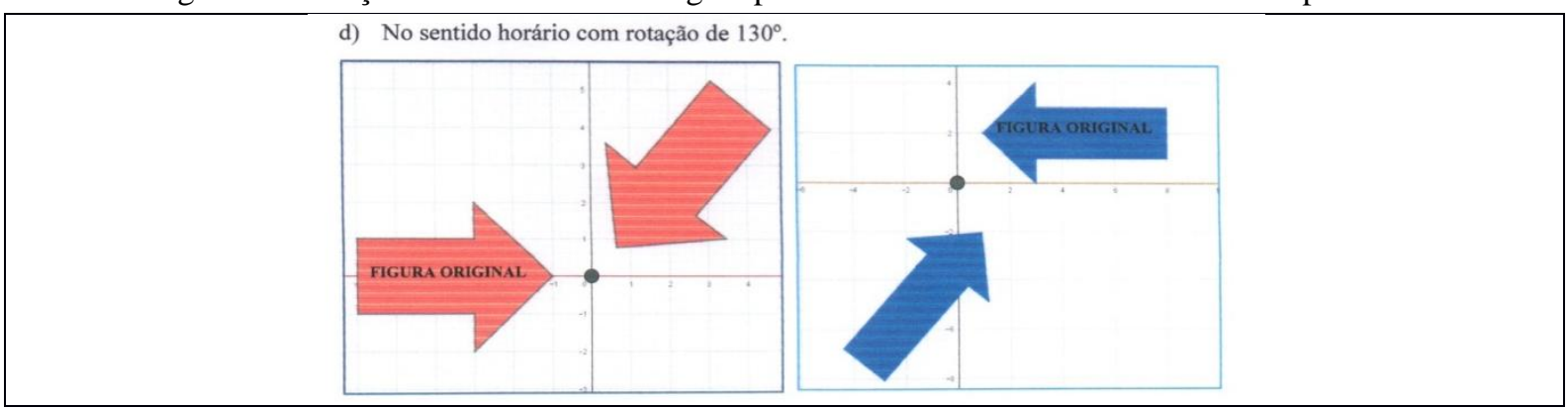

Fonte: Professores A e E.

$\mathrm{Na}$ figura 4, é interessante observar que o professor A girou a figura original em $130^{\circ}$ no sentido horário, distintamente do professor E, que a girou no sentido anti-horário. Ainda, a partir das figuras, pode-se observar que houve rotações no sentido horário e anti-horário e o ponto de referência da mensuração também foi variável. Ademais, após concluírem as resoluções dessa atividade, apresentadas nas Figuras 01, 02, 03 e 04, verificou-se um avanço significativo em relação ao conhecimento adquirido sobre o software, pois, no início da formação, os professores tinham dificuldades em explorar as ferramentas do GeoGebra. 
Os professores ficaram admirados com as resoluções elaboradas nesse primeiro momento do encontro, bem com, com a realização do trabalho desenvolvido com tecnologia. O professor A comentou: "Uau nunca pensei que faria umas figuras tão lindas em tão pouco tempo". A abordagem do professor despertou a curiosidade dos outros, o que levou à comparação das atividades realizadas entre eles e à conclusão de que todas estavam bem resolvidas.

Diante do exposto, enfatiza-se que o primeiro momento desse encontro foi bemsucedido e o software foi eficaz, por ter auxiliado os professores a construírem resoluções Matemáticas de forma rápida, dinâmica e adequada. Levy (2011) afirma que as tecnologias intelectuais eficazes resultam muitas vezes desta aliança entre a visibilidade imediata (requerendo aprendizagem) e a facilidade de operação.

Prosseguindo com o estudo de isometrias de rotação, além de abordar atividades de exploração do software GeoGebra, foram apresentadas algumas questões que exigiam conhecimentos teóricos sobre rotação. Na Figura 5, os professores foram requeridos a determinar o ponto de pares ordenados, supondo onde cada letra ficaria, se houvesse rotações múltiplas em diferentes graus.

Figura 5 - Pontos de rotação determinados por suposição da professora B

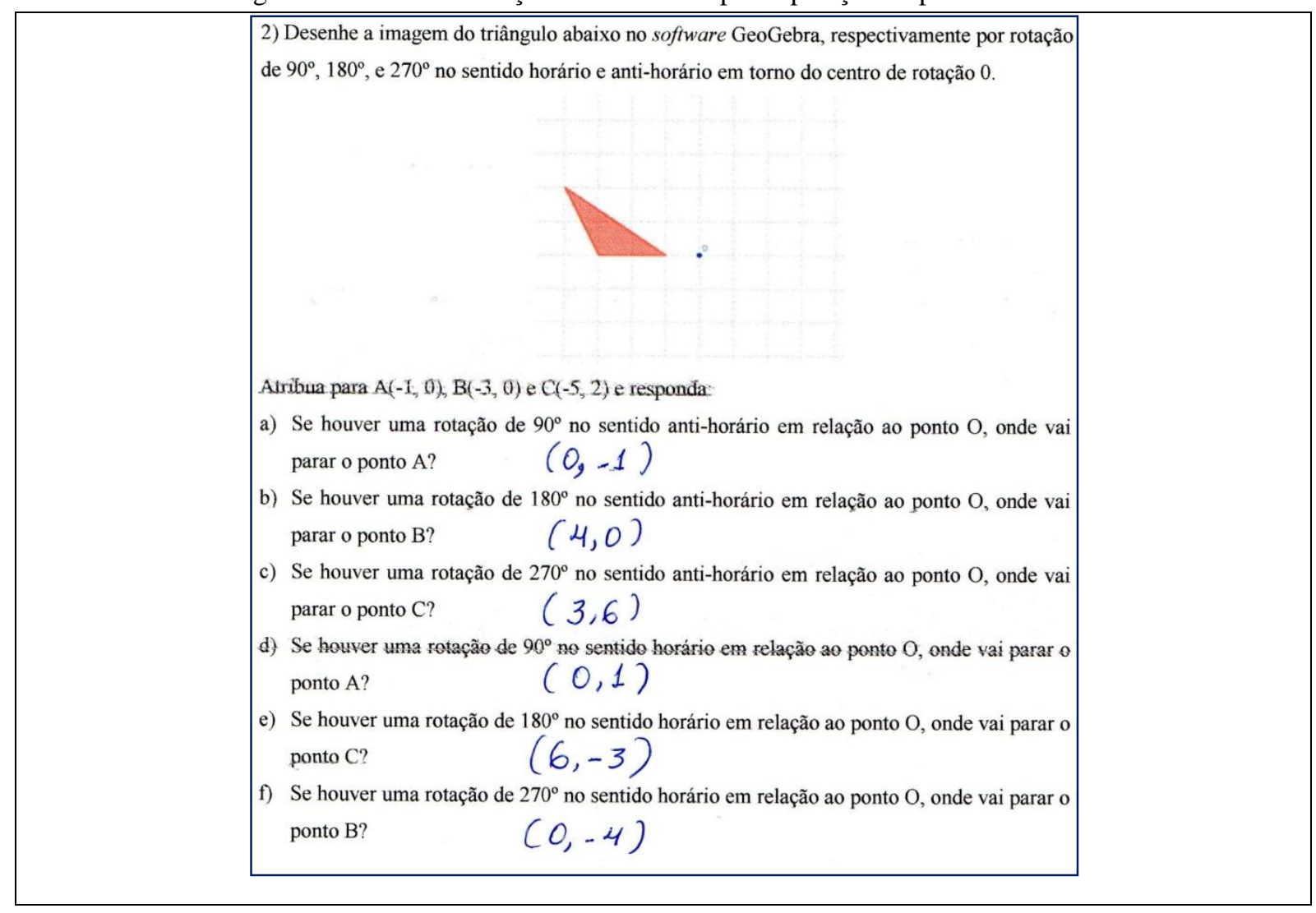

Fonte: Professora B. 
Para conferir se os pontos apresentados na Figura 5 estavam corretos, os professores, utilizando o software, desenharam um polígono, atribuindo os pontos determinados pelos professores pesquisadores na atividade. Em seguida, realizaram movimentos simultaneamente por rotação de $90^{\circ}, 180^{\circ}$ e $270^{\circ}$ da figura nos sentidos anti-horário e horário. As Figuras 6,7 e 8 são produções de três professores para a tarefa.

Figura 6 - Imagem com rotação de $90^{\circ}$ no sentido anti-horário e no sentido horário

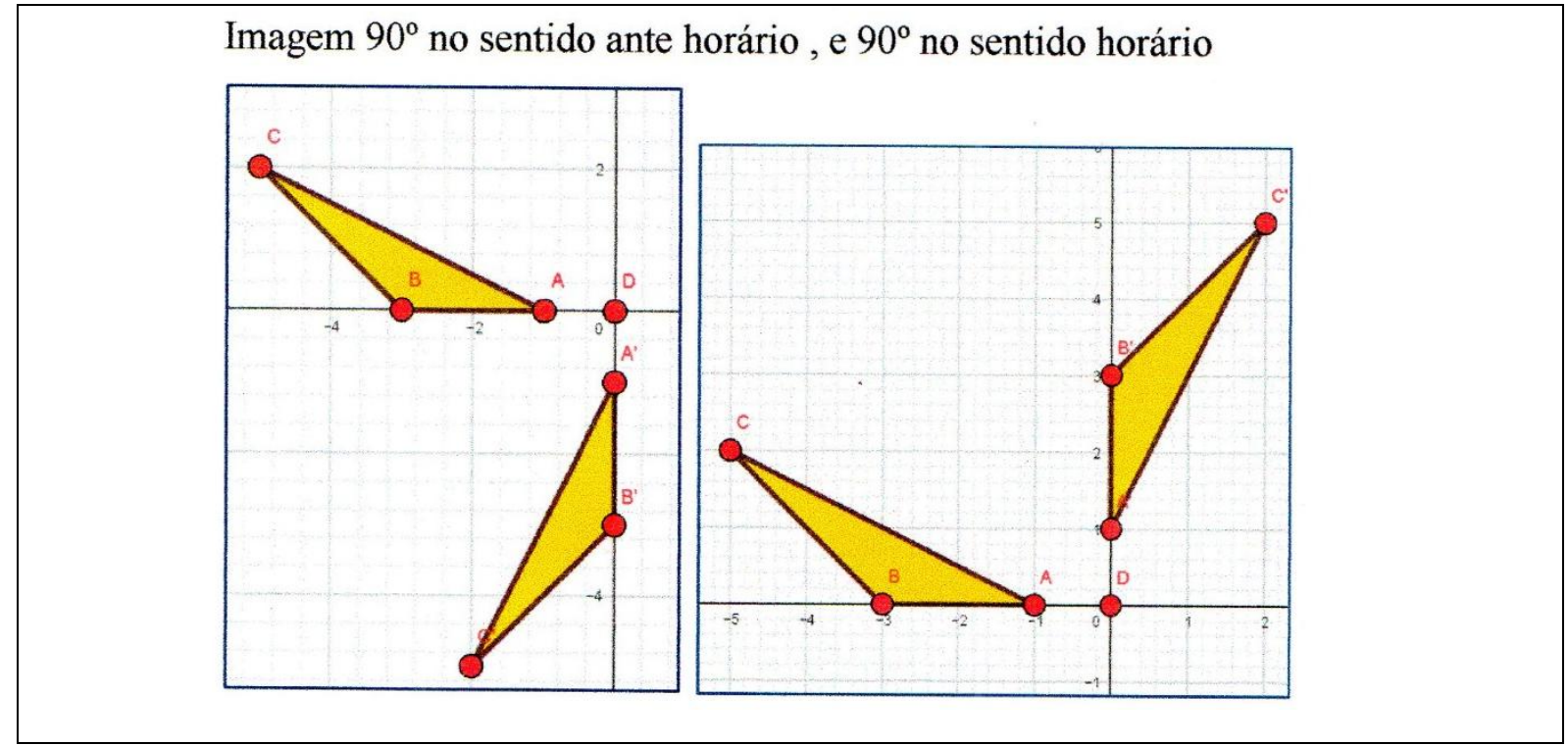

Fonte: Professor A.

Figura 7 - Imagem com rotação de $180^{\circ}$ no sentido anti-horário

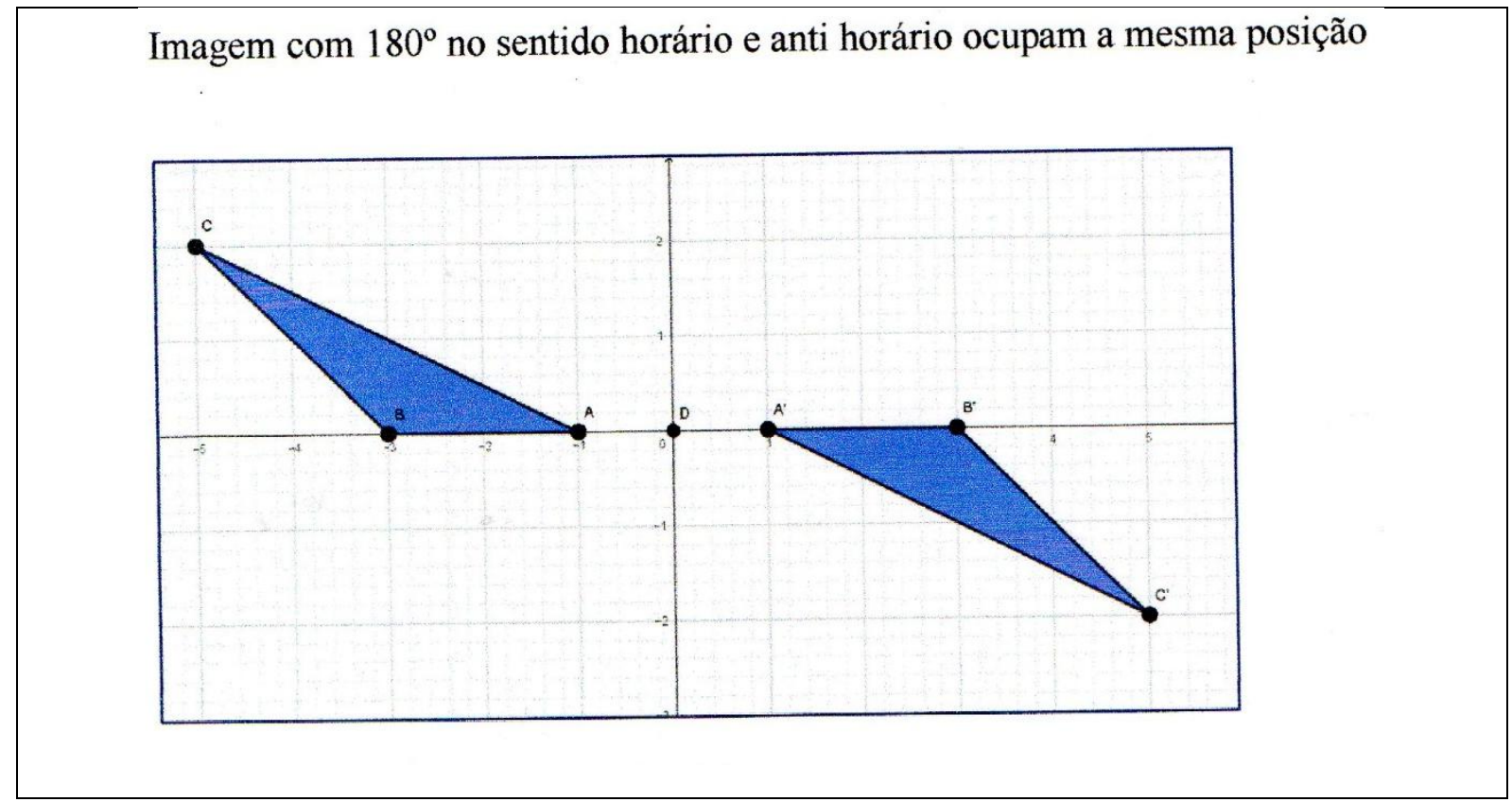

Fonte: Professora B. 
Figura 8 - Imagem com rotação de $270^{\circ}$ no sentido anti-horário e no sentido horário

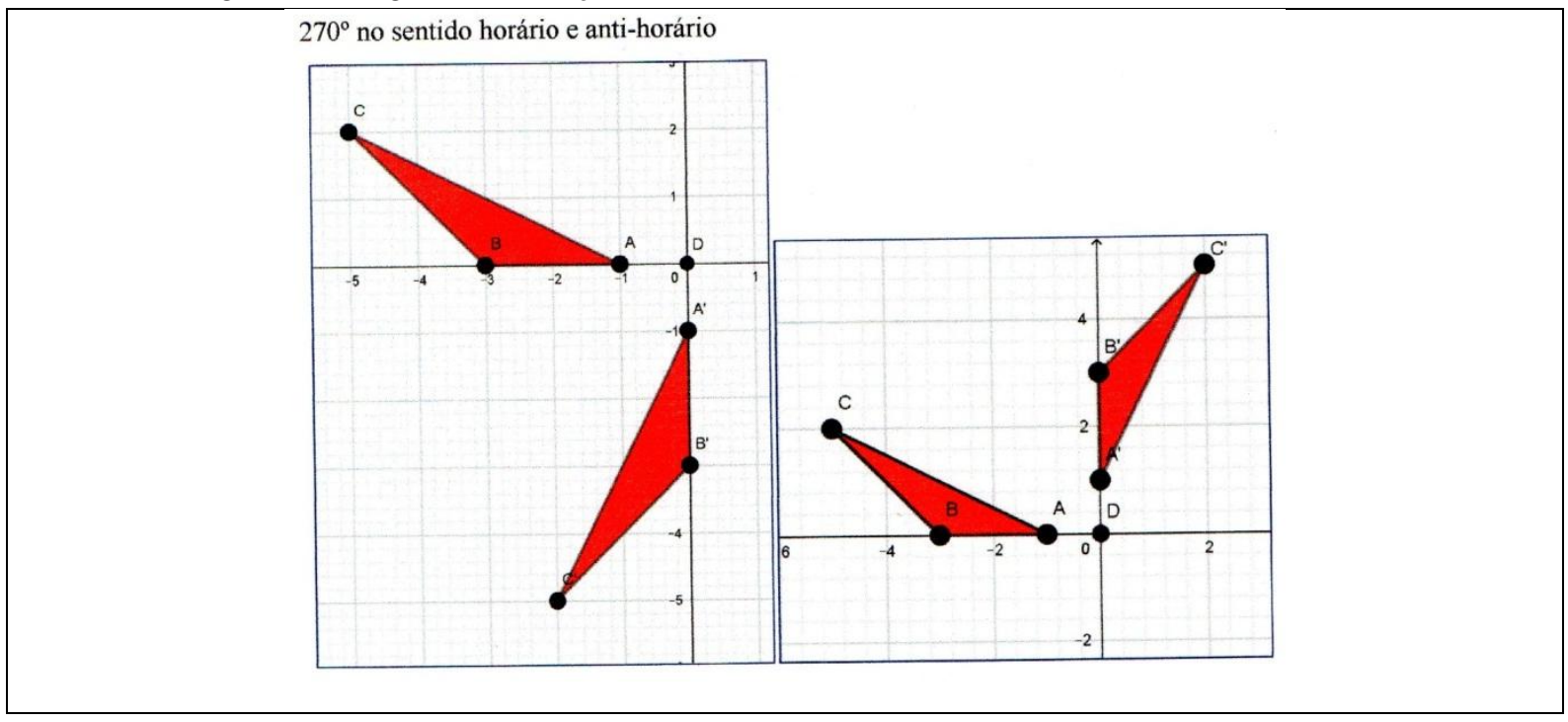

Fonte: Professora C.

Observando as rotações realizadas nas imagens desenhadas pelos professores, pode-se verificar que houve acertos nas suposições mencionadas na Figura 5, e também nos movimentos de rotação realizados nas Figuras 06, 07 e 08. Portanto, infere-se que os bons resultados obtidos revelam o sucesso da temática abordada e o potencial do software utilizado e, portanto, dos indícios do aprendizado realizado.

Percebe-se que as atividades desenvolvidas nesse encontro levaram os professores a refletirem sobre como atuam na sala de aula, bem como, despertou neles a estima pelo software GeoGebra. À luz de Freitas (2009), pode-se inferir que o trabalho realizado gerou o envolvimento dos professores no sentido de compreenderem melhor o valor dessa tecnologia e desejarem incluir, em suas práticas pedagógicas, atividades dela decorrentes. Dessa forma, os resultados também apontaram para mudanças futuras na postura desses educadores, frente às novas tecnologias. Para evidenciar esse fato, descreve-se um dos comentários feitos pela professora B durante o encontro:

\begin{abstract}
Até agora essa foi à atividade mais legal. Não me interessava para usar as tecnologias na sala de aula, porque pensava que a única coisa que podia fazer com ela, era colocar os alunos para pesquisar palavras. Como em Matemática quase não tem palavras para pesquisa significados, não utilizava. Agora sei que as tecnologias oferecem programas que podemos explorar matemática, como é o caso do GeoGebra.
\end{abstract}

A desenvoltura dos professores e também os comentários elucidados durante o encontro permitem inferir, com base em Borba e Penteado (2015), que, quanto mais o professor se inserir no mundo das tecnologias, mais ele corre o risco de deparar-se com situações matemáticas. Como se pode observar, esse processo de integração, ao mesmo tempo em que despertou o 
interesse dos educadores pelas tecnologias, fez com que percebessem o quanto ainda precisam conhecer a respeito delas para poderem inseri-las em suas práticas pedagógicas.

No encontro seguinte, foi entregue aos professores a fotocópia do material e prosseguiuse com o estudo de isometrias de rotação. Com maior entrosamento e mais conhecimento, os professores conseguiram manusear o software GeoGebra a ponto de construírem soluções para todas as situações propostas, praticamente sem precisar da intervenção da pesquisadora formadora. Esse fato revelou que estavam cada vez mais em harmonia com a tecnologia utilizada, mostrando interesse e aptidão para a produção de novos conhecimentos. As Figuras 9 e 10 abordam parte dos conhecimentos teóricos dos professores sobre isometrias do tipo rotação.

Figura 9 - Pontos a partir de supostas rotações

3) Desenhe a figura abaixo a partir dos pontos $\mathrm{A}(3,3), \mathrm{B}(1,2), \mathrm{C}(4,1), \mathrm{D}(7,2)$ e $\mathrm{E}(4,2)$.

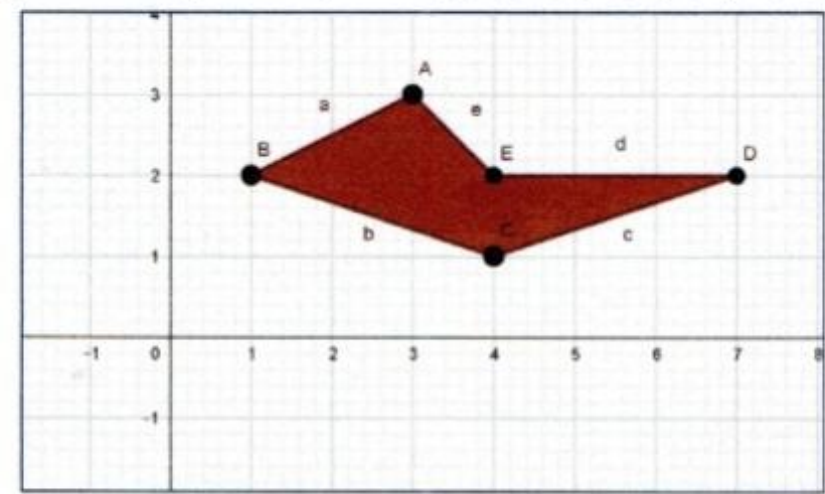

a) Se houver uma rotação de $90^{\circ}$ em relação ao ponto $\mathrm{D}$ no sentido anti-horário, onde vai se situar o ponto $\mathrm{D}$ ? $\quad \mathrm{D}(7,2)$

b) Se houver uma rotação de $180^{\circ}$ em relação ao ponto $\mathrm{B}$ no sentido anti-horário, onde vai se situar o ponto $\mathrm{B}$ ? $\quad B(1,2)$

c) Se houver uma rotação de $180^{\circ} \mathrm{em}$ relação ao ponto $\mathrm{B}$ no sentido horário, onde vai se situar o ponto $\mathrm{B}$ ? (B 1,2)

d) Se houver uma rotação de $45^{\circ} \mathrm{em}$ relação ao ponto $\mathrm{C}$ no sentido anti-horário, onde vai se situar o ponto $\mathrm{E}$ ? $\quad E(3.29,171)$

e) Se houver uma rotação de $120^{\circ}$ em relação ao ponto $\mathrm{E}$ no sentido anti-horário, onde vai se situar o ponto $\mathrm{E}$ ? $\quad E(4.2)$

Fonte: Professora D. 
Figura 10 - Argumentos usados para resolver as atividades da Figura 9

f) Como você pensou para responder a atividade?

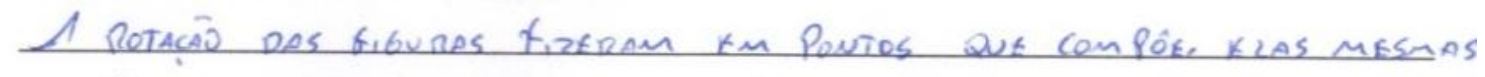

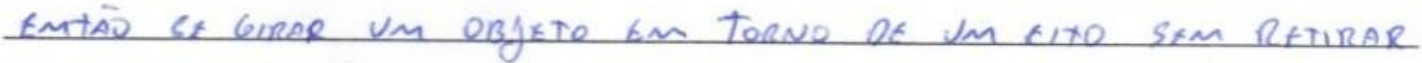

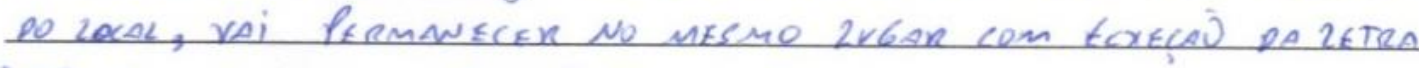
"D" Qve Giramos o forto " 6 " fm Torvo of "C"

g) Confira agora usando o software GeoGebra. Quais respostas você errou? Por quê? NTNHUA

Fonte: Professor A.

Prosseguindo o estudo de isometrias de rotação, o GeoGebra foi utilizado para construir mais um polígono, realizar outros movimentos de rotação, bem como, para conferir os pontos propostos pelos professores na atividade da Figura 9. Durante a resolução das questões apresentadas na sequência, nas Figuras 11, 12, 13 e 14, em nenhum momento o professor formador foi questionado acerca de dúvidas em relação ao conteúdo, tampouco, chamado para auxiliar no manuseio do software. Diante disso, infere-se que os professores já apresentavam maior agilidade no uso do software, bem como, maior domínio do conteúdo apresentado. Cabe salientar que o professor A, ao conferir as respostas expressas sem o uso do software, afirmou que não errou nenhum ponto, ou seja, compreendeu corretamente o que é uma isometria de rotação.

Figura 11 - Imagem com rotação de $45^{\circ}$ no sentido anti-horário

Rotação de $45^{\circ}$ no sentido anti-horário em relação ao ponto C.

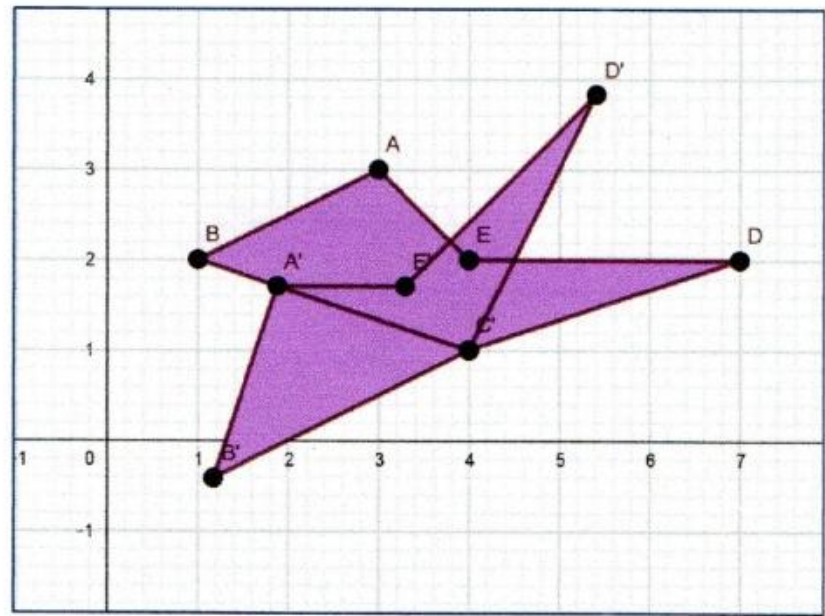

Fonte: Professora B. 
Figura 12 - Imagem com rotação de $90^{\circ}$ no sentido anti-horário

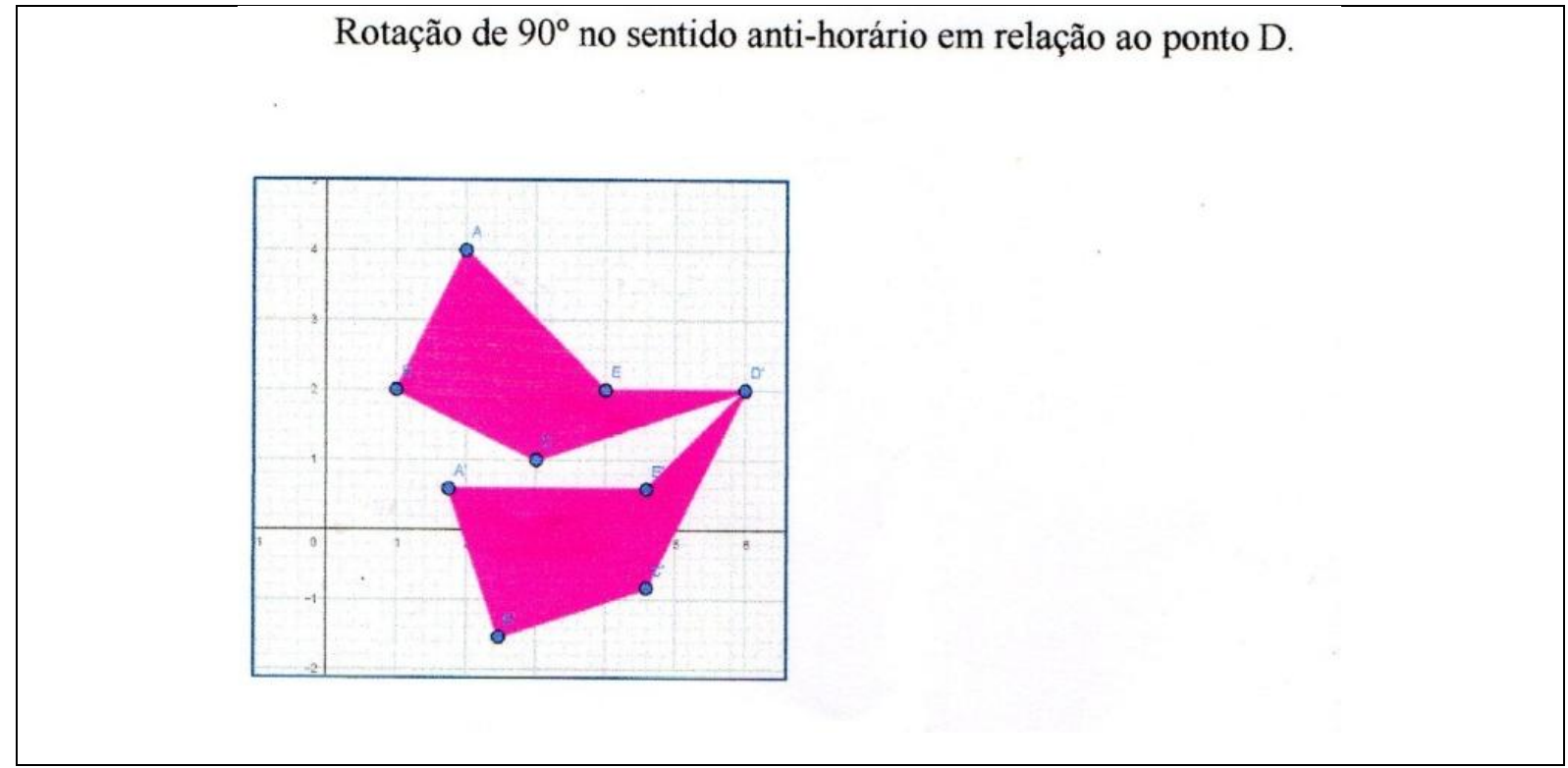

Fonte: Professora C.

Figura 13 - Imagem de rotação de $120^{\circ}$

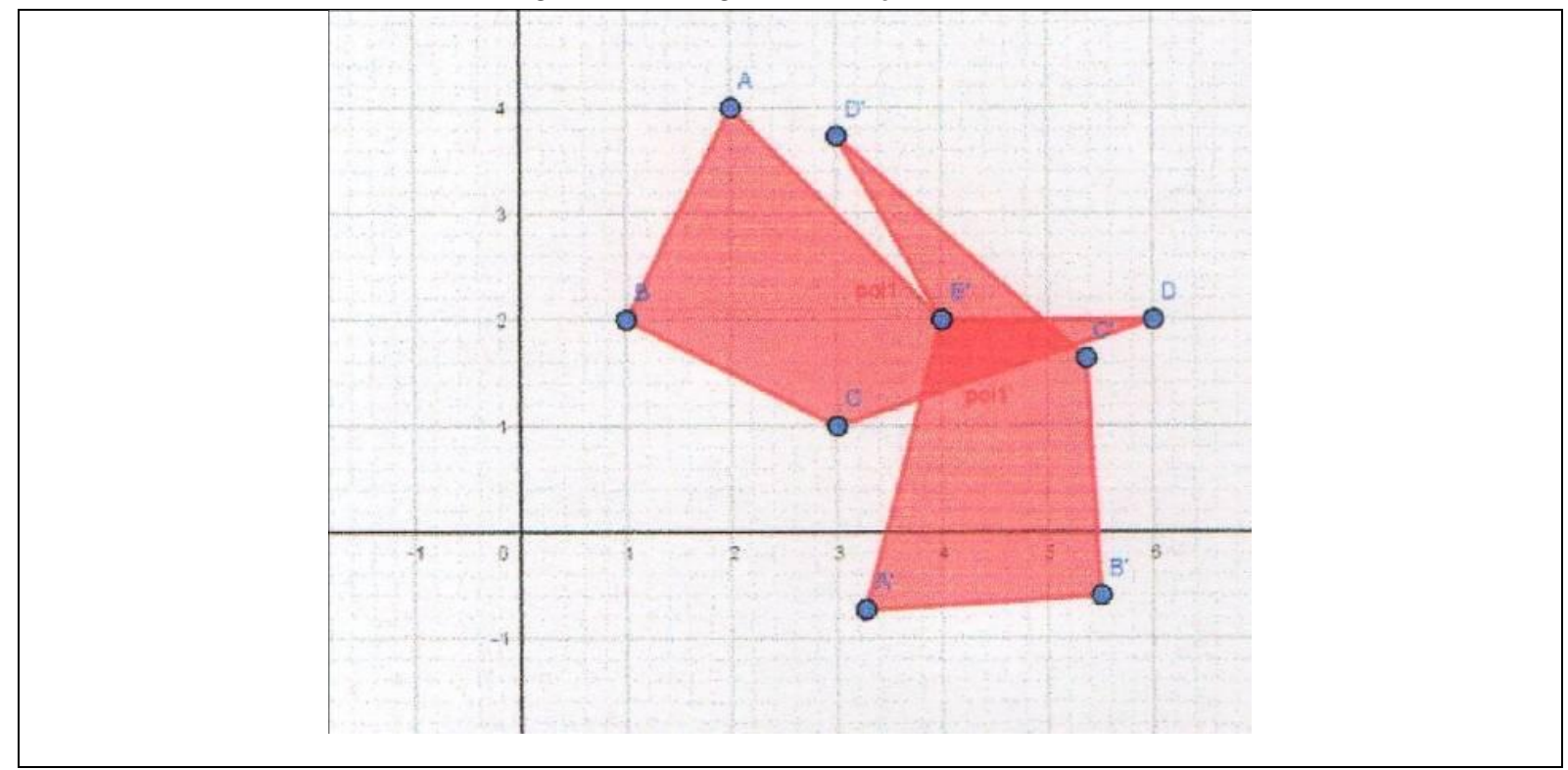

Fonte: Professora D. 
Figura 14 - Imagem com rotação de $180^{\circ}$ no sentido horário

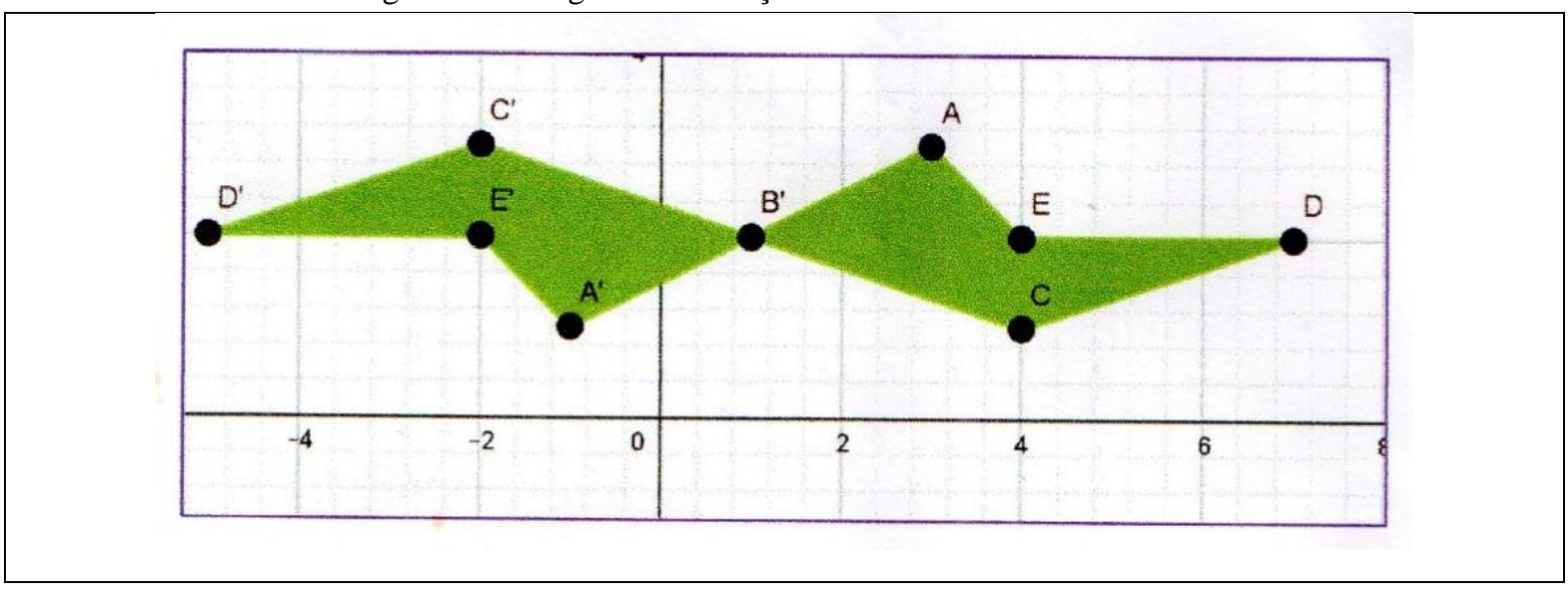

Fonte: Professor E.

Assim, infere-se, com base em Carvalho e Gil-Pérez (2011), que a formação continuada de professores deveria dar maior ênfase a conteúdos que os educadores terão de ensinar. Deveriam proporcionar uma sólida compreensão dos conceitos fundamentais, familiarizando o professor com o processo de raciocínio que subjaz à construção de conhecimentos.

Analisando o comportamento dos professores durante o encontro e as respostas elencadas, afirma-se que todos se posicionaram positivamente em relação ao software GeoGebra. Ainda, usaram corretamente os menus necessários para a efetivação das atividades desenvolvidas durante o encontro, permitindo aos autores do relato enfatizar que os resultados foram profícuos e as resoluções incontestáveis. Assim, entende-se que essa formação assumiu diversos papéis, incorporando as tecnologias ao contexto desses professores e preparando-os para promover futuras aprendizagens contextualizadas, como apregoa Freitas (2009).

\section{CONCLUSÃo}

O estudo de isometrias de rotação desenvolvido por meio do software GeoGebra foi complementar para a prática desses professores, pois, além de dinâmico e desafiador, demonstrou algumas das insuficiências de suas práticas pedagógicas. Tal afirmação fica evidente numa das falas da professora $\mathrm{B}$, já mencionada: "Agora sei que as tecnologias oferecem programas que podemos explorar matemática, como é o caso do GeoGebra". Também promoveu um conhecimento que ainda não existia, conforme outra fala da professora já mencionada, em um dos momentos do estudo: "Essa formação me fez ver como eu era retrógrada, abriu minha mente para o mundo moderno, portanto para trabalhar com mais motivação e principalmente inovação" (PROFESSORA B). 
Diante disso, constata-se que houve aprendizado, visto que os professores aprenderam a manejar o software GeoGebra, estando, portanto, capacitados para fortalecer os seus afazeres pedagógicos com o estudo de isometrias desenvolvido nesse trabalho. Isso pode ser constatado nas características das atividades apresentadas no decorrer do estudo, nos relatos de cada professor e no modo como se portaram no decorrer da formação. Nessas condições, segundo Tajra (2012), a partir da capacitação para a utilização de diferentes tecnologias e do entendimento das características do software, os professores estão preparados para planejar aulas e utilizar as tecnologias como ferramenta pedagógica.

Diante disso, conclui-se que a prática moveu os sentimentos desses educadores. Fez fluir em cada um deles o desejo de incorporar mudanças em suas práticas pedagógicas e assumir novas posturas, frente às tecnologias educacionais. Sobre essas mudanças, o professor E elucidou:

Esta formação me trouxe empolgação e me fez mudar a minha forma de pensar, de preparar minhas aulas, de trabalhar, enfim, posso dizer que agora estou com o sentimento de que quero mudar em muitos aspectos, inclusive inovar e usar as tecnologias em minhas aulas.

Infere-se que os resultados da formação foram relevantes e significativos para inserir mudanças necessárias à prática desses professores, que, antes da formação, não tinham nenhum contato com o software GeoGebra. Assim, como afirma Freitas (2009), os professores se situaram em relação ao letramento digital2 e à aprendizagem em tempos de inovações tecnológicas, compreendendo, a partir daí, o contexto no qual estão inseridos.

Os professores expressaram estar motivados, tecnologicamente capacitados para traçar novos caminhos junto com seus alunos. Enfim, pode-se sumarizar que os resultados apontaram que o curso de formação continuada contribuiu para a incorporação do software GeoGebra, como recurso tecnológico, na prática dos professores, indicando mudanças futuras, dado o interesse demonstrado nos encontros de formação

\section{REFERÊNCIAS}

BORBA, Marcelo Carvalho; ARAÚJO, Jussara de Loiola. Pesquisa Qualitativa em Educação Matemática. 5. ed. Belo Horizonte, MG: Ed. Autêntica, 2013.

BORBA, Marcelo Carvalho; PENTEADO, Miriam Godoy. Informática e Educação Matemática. 5. ed. Belo Horizonte, MG: Ed. Autêntica, 2015.

\footnotetext{
2 Segundo Xavier (2004), letramento digital tem relação com modificações ocorridas os modos de ler e escrever os códigos e sinais verbais e não verbais que passaram a ser lidos na tela do computador, distintamente de como se faz nos livros.
} 
BORBA, Marcelo Carvalho; SILVA, Ricardo Scucuglia R.; GADANIS, George. Fases das Tecnologias Digitais em Educação Matemática: sala de aula e internet em movimento. Belo Horizonte, MG: Ed. Autêntica, 2014.

CARVAlHO, Anna Maria Pessoa; GIL-PÉREZ, Daniel. Formação de Professores de Ciências: tendências e inovações. 10. ed. São Paulo, SP: Ed. Cortez, 2014.

FREITAS, Maria Teresa de Assunção. (Org.). Cibercultura e formação de professores. Belo Horizonte, MG: Ed. Autêntica, 2009.

GEWEHR, Diógenes. Tecnologias Digitais de Informação e Comunicação (TDICs) na escola e em ambientes não escolares. 2016. 136 f. Lajeado: Dissertação de Mestrado (Mestrado em Ensino de Ciências Exatas) - Centro Universitário UNIVATES, Rio Grande do Sul, Lajeado, 2016. Disponível em:

<https://www.univates.br/bdu/bitstream/10737/1576/1/2016DiogenesGewehr.pdf>. Acesso em: 17 mar. 2019.

GODOY, Arilda Schmidt. Pesquisa qualitativa tipos fundamentais. [S.1.], 2005. Disponível em: 〈http://www.scielo.br/pdf/rae/v35n3/a04v35n3.pdf>. Acesso em: fev. 2017.

LÉVY, Pierre. As Tecnologias da Inteligência: o futuro do pensamento na era da informática. 2. ed. 1. reimpr. São Paulo, SP: Editora 34, 2011.

LEWGOY, Alzira Maria Baptista; ARRUDA, Marina Patrícia de. Novas tecnologias na prática profissional do professor universitário: a experiência do diário digital. Revista Textos e Contextos: coletâneas em Serviço Social, Porto Alegre: EDIPUCRS, n. 2, p. 115-130, 2004.

MARCONI, Marina de Andrade; LAKATOS, Eva Maria. Metodologia do trabalho Científico. 7. ed. [S.1.]: Editora Atlas, 2014.

SILVA, Mozart Linhares da (Org.). Novas Tecnologias: educação e Sociedade na Era da Informação. Belo Horizonte, MG: Ed. Autêntica, 2008.

TAJRA, Sanmya Feitosa. Informática na educação: novas ferramentas pedagógicas para o professor da atualidade. 9. ed. São Paulo: Editora Érica, 2012.

XAVIER, Antonio Carlos. Letramento digital e ensino. In. SANTOS, Carmi Ferraz; MENDONÇA, Márcia (orgs). Alfabetização e letramento: conceitos e relações. Belo Horizonte: Autêntica, pp. 133-148, 2005.

Recebido em: 01 de fevereiro de 2019. Aprovado em: 15 de abril de 2019. 